\title{
Letter to the Editor and Response
}

\author{
HHV8 is not limited to Kaposi's sarcoma
}

Modern Pathology (2005) 18, 1148-1150. doi:10.1038/modpathol.3800441

To the editor: We read with interest the recent paper by Patel et $a l^{1}$ in which they report strong immunoreactivity for human herpes virus 8 (HHV8) latent nuclear antigen-1 (LNA-1) in all (21/21 cases) of their Kaposi sarcoma lesions, whereas all of their non-Kaposi's sarcoma cases (including hemangioma, angiosarcoma, etc) were negative for this antigen. Their finding corroborates those of other similar studies using reverse transcription polymerase chain reaction (RT-PCR) ${ }^{2}$ and immunohistochemistry ${ }^{3,4}$ directed against LNA-1. The deduction reached by Patel and colleagues is that LNA-1 is a highly sensitive and specific marker of HHV8 infection in paraffin-embedded tissue sections of Kaposi's sarcoma, and therefore provides a useful tool for differentiating Kaposi's sarcoma from its mimics, which do not express HHV8 LNA-1. ${ }^{1}$ However, we would like to point out that the prevalence of HHV8 seropositivity far exceeds that of Kaposi's sarcoma. ${ }^{5,6}$ Moreover, Patel et al conducted their study in Cleveland, Ohio in the United States of America (USA) where the prevalence of HHV8 infection is reported to be very low. ${ }^{6}$ By comparison, in sub-Saharan Africa and the Mediterranean region HHV8 seropositivity in the general population is high. ${ }^{6}$ Therefore, it is plausible in the correct setting for HHV8 to be detected (by molecular or other means) in nonKaposi's sarcoma lesions in those individuals who harbor HHV8. Patel et al did not report the HHV8 infectious status of their non-Kaposi's sarcoma cases. They did, however, correctly point out that other non-Kaposi's sarcoma vascular lesions (eg reactive angioendotheliomatosis) may stain positive for LNA-1 in lesional cells. ${ }^{1}$ Some investigators (from the USA) have detected HHV8-like DNA sequences (by PCR) in several (7/24) angiosarcomas. ${ }^{7}$ Another, even more illustrative case, was the demonstration of HHV8 in a dermatofibroma by both PCR and in situ hybridization (ISH) in a patient who was HIV-negative but seropositive for HHV-8 antibodies. ${ }^{8}$ These authors further indicated that the presence of HHV8 in the studied dermatofibroma was probably blood-borne due to viremia and not due to viral replication in tumor cells. ${ }^{8}$ The purpose of this letter is to reiterate these findings and to emphasize that the differential diagnosis of Kaposi's sarcoma from its mimics should not rely solely on the presence or absence of HHV8 in lesional tissue.

Liron Pantanowitz ${ }^{1}$, Gerladine S Pinkus ${ }^{2}$, Bruce J Dezube $^{3}$ and Steven R Tahan ${ }^{1}$

${ }^{1}$ Department of Pathology, Beth Israel Deaconess Medical Center, Boston, MA, USA;

${ }^{2}$ Department of Pathology, Brigham and Women's Hospital, Harvard Medical School, Boston, MA, USA and ${ }^{3}$ Department of Medicine (Hematology-Oncology Division), Beth Israel Deaconess Medical Center, Boston, MA, USA

\section{References}

1 Patel RM, Goldblum JR, Hsi ED. Immunohistochemical detection of human herpes virus-8 latent nuclear antigen-1 is useful in the diagnosis of Kaposi sarcoma. Mod Pathol 2004;17:456-460.

2 Nuovo M, Nuovo G. Utility of HHV8 RNA detection for differentiating Kaposi's sarcoma from its mimics. J Cutan Pathol 2001;28:248-255.

3 Hong A, Davies S, Lee CS. Immunohistochemical detection of the human herpes virus 8 (HHV8) latent nuclear antigen-1 in Kaposi's sarcoma. Pathology 2003;35:448-450.

4 Schwartz EJ, Dorfman RF, Kohler S. Human herpesvirus-8 latent nuclear antigen-1 expression in endemic Kaposi sarcoma: an immunohistochemical study of 16 cases. Am J Surg Pathol 2003;27:1546-1550.

5 Dedicoat M, Newton R. Review of the distribution of Kaposi's sarcoma-associated herpesvirus (KSHV) in Africa in relation to the incidence of Kaposi's sarcoma. Br J Cancer 2003;88:1-3.

6 Dukers NH, Rezza G. Human herpesvirus 8 epidemiology: what we do and do not know. AIDS 2003;17:1717-1730.

7 McDonagh DP, Liu J, Gaffey MJ, et al. Detection of Kaposi's sarcoma-associated herpesvirus-like DNA sequence in angiosarcoma. Am J Pathol 1996;149:1363-1368.

8 Kazakov DV, Schmid M, Adams V, et al. HHV-8 DNA sequences in the peripheral blood and skin lesions of an HIV-negative patient with multiple eruptive dermatofibromas: implications for the detection of HHV-8 as a diagnostic marker for Kaposi's sarcoma. Dermatology 2003;206:217-221.

Publisher's Note: The Response to this letter was published in the last issue of Modern Pathology (18, 1011-1012) without the original letter by Pantanowitz et al. We have chosen to republish the Response to show the correspondence in its entirety. 


\section{Response to Pantanowitz et al}

Reprinted from Modern Pathology (2005) 18, 1011-1012. doi:10.1038/modpathol.3800376

In reply: We appreciate the comments of Pantanowitz et al regarding our paper on the utility of the detection of HHV-8 LNA-1 by immunohistochemistry in the diagnosis of Kaposi's sarcoma. ${ }^{1}$ They appear to be concerned because (1) the prevalence of HHV-8 is low in Cleveland, OH but high in other areas and that we did not report serologic data on our patients, and (2) that HHV-8 can be detected by molecular methods in nonKaposi's sarcoma lesions from patients who harbor HHV-8.

It is true that we did not report the HHV-8 serologic status of patients in our study and that we conducted our study in Cleveland where the prevalence of HHV-8 is likely to be low. Indeed, the seroprevalence of HHV-8 in the United States population as a whole is estimated at $3.5 \%,{ }^{2}$ much lower than in many high-prevalence African countries. ${ }^{3}$ Since our study was a retrospective study, we did not have serological data on our patients. Our manuscript showed that HHV-8 can be detected in tumor cells of virtually all cases of Kaposi's sarcoma. Others have shown similar results, including in endemic Kaposi's sarcoma. ${ }^{4-6}$ None of these studies reported HHV-8 serologic data. While this information would be useful, we believe it does not significantly detract from our overall conclusion that immunohistochemical demonstration of HHV-8 virus in tumor cells of vascular and spindle cell lesions is a useful tool (in association with histopathologic and clinical features) when the diagnosis of Kaposi's sarcoma seems reasonable. We do not advocate diagnosis of Kaposi's sarcoma based on presence of the virus alone due to the possibility of finding HHV-8 in other types of lesions, a view shared by other investigators. ${ }^{4,5}$

As to the second point, we agree with Pantanowitz et al that molecular methods can detect HHV-8 in non-Kaposi's sarcoma lesions. However, PCR-based detection methods for HHV-8 are very sensitive and can produce positive results due to the presence of 'bystander' virus contamination. Previous studies have found HHV-8 sequences by PCR in peripheral blood mononuclear cells in HIV-infected and uninfected patients with Kaposi's sarcoma, ${ }^{7}$ and in a healthy blood donor. ${ }^{8}$ We and other investigators agree that the presence of such bystander cells was probably responsible for the few series that describe HHV-8 in AS., ${ }^{4,5}$ In the AS study cited by Pantanowitz et al, no histopathological description, photomicrographs, or viral cellular localization of the analyzed cases of Kaposi's sarcoma were included. ${ }^{10}$ Importantly, the findings of that study have not been validated by other investigators in a larger series. ${ }^{9}$ Finally, Kazakov and colleagues (as cited by Pantanowitz) reported HHV-8 positivity by PCR in a case of multiple eruptive dermatofibromas in an HIV-negative patient. However, in situ hybridization failed to localize HHV-8 to tumor cells. They correctly concluded that the PCR positivity was probably due to blood-born viremia and/or contamination by HHV-8-infected monocytes and lymphyocytes. ${ }^{11}$ These observations demonstrate that cellular localization of HHV-8 by immunohistochemistry is more useful for routine diagnostic purposes than standard PCR amplification-based methods.

In conclusion, the use of HHV-8 immunohistochemistry is a very useful tool that, in conjunction with other clinical, morphologic, and phenotypic features, should enable the practicing surgical pathologist to arrive at the correct diagnosis. We do not suggest that HHV-8 immunohistochemistry be used as a stand-alone test in which a positive result equates to a diagnosis of Kaposi's sarcoma.

\section{Rajiv M Patel, John R Goldblum and Eric D Hsi Division of Pathology and Laboratory Medicine, Department of Clinical Pathology L30, 9500 Euclid Avenue, Cleveland, $\mathrm{OH} 44195$, USA}

\section{References}

1 Patel RM, Goldblum JR, Hsi ED. Immunohistochemical detection of human herpes virus-8 latent nuclear antigen-1 is useful for the diagnosis of Kaposi sarcoma. Mod Pathol 2004;17:456-460.

2 Pellett PE, Wright EA, Engels EA, et al. Multicenter comparison of serologic assays and estimation of human herpesvirus 8 seroprevalence among US blood donors. Transfusion 2003;43:1260-1268.

3 Dedicoat M, Newton R. Review of the distribution of Kaposi's sarcoma-associated herpesvirus (Kaposi's sarcomaHV) in Africa in relation to the incidence of Kaposi's sarcoma. Br J Cancer 2003;88:1-3.

4 Cheuk W, Wong KOY, Cesar SC, et al. Immunostaining for human herpesvirus 8 latent nuclear antigen-1 helps distinguish Kaposi sarcoma from its mimickers. Am J Clin Pathol 2004;121:335-342.

5 Robin YM, Guillou L, Miches JJ, et al. Human herpesvirus 8 immunostaining: a sensitive and specific method for diagnosing Kaposi sarcoma in paraffin-embedded sections. Am J Clin Pathol 2004; 121:1-5.

6 Schwartz EJ, Dorfman RF, Kohler S. Human herpresvirus-8 latent nuclear antigen-1 expression in endemic Kaposi sarcoma. Am J Surg Pathol 2003;27:1546-1550. 
7 Ambroziak JA, Blackbourn DJ, Kerndier B, et al. Herpes-like sequences in HIV-infected and uninfected Kaposi's sarcoma patients. Science 1995;268:582-583.

8 Blackbourn DJ, Ambroziak J, Lennette E, et al. Infectious human herpesvirus 8 in a healthy North American blood donor. The Lancet 1997;349:609-611.

9 Lasota J, Miettinen M. Absence of Kaposi's sarcomaassociated virus (human herpesvirus-8) sequences in angiosarcoma. Virchow's Arch 1999;434:51-56.
10 McDonach DP, Liu J, Gaffey MJ, et al. Detection of Kaposi's sarcoma-associated herpesvirus-like DNA sequences in angiosarcoma. Am J Pathol 1996;149:1363-1368.

11 Kazakov DV, Schmid M, Adams V, et al. HHV-8 DNA sequences in the peripheral blood and skin lesions of an HIV-negative patient with multiple eruptive dermatofibromas: implications for the detection of HHV-8 as a diagnostic marker for Kaposi's sarcoma. Dermatology 2003;206:217-221. 